\title{
Motivational Interviewing in Pediatric Dentistry: Role in Behavior Management
}

\author{
Sonu Acharya
}

\begin{abstract}
There is a rise in demand for pediatric dentists in pediatric settings to look into not only the physical but also the psychological health of their child and adolescent patients. Brief interventions (Bls), and in particular motivational interviewing (MI), offers an ideal means of changing behavioral, developmental and social problems within the scenario of dental practice in pedodontics. Motivational interviewing is a well-established and tested method of counseling made by Miller and Rollnick and thought of as a useful modification strategy in treatment of lifestyle diseases. This makes the patients motivated and helps them to the process of change. Once the healthier behavior is learned, it can increase or decrease the likelihood for sustained behavior change. Motivational interviewing is a psychological instrument developed in recent times with main objective of providing patients, including children with low motivation to achieve and retain behavioral changes. Motivational interviewing can be used in pedodontics for increased capability in proper brushing, flossing, and application of fluoride varnish. Thus, this review is aimed to know the role of $\mathrm{MI}$ in pediatric dentistry as a whole.
\end{abstract}

Keywords: Behavior, Behavior change theory, Motivational interviewing, Pediatric dentistry.

Journal of South Asian Association of Pediatric Dentistry (2019): 10.5005/jp-journals-10077-3030

\section{INTRODUCTION}

Oral health is a neglected avenue in front of overall health and has historically been low on demand of national policy makers. ${ }^{1}$ The reasons are complicated and many. In many countries, oral health is neglected in national health surveys. And, even though data are collected, it is usually alone notwithstanding the general health. ${ }^{2}$ Dentists have not taken due interest in promoting good oral health, preferring always to treat instead of preventing oral diseases. And, in the view that poor oral health causes morbidity rather than mortality, governments have given oral conditions little importance than other, more life-threatening diseases. ${ }^{3}$ Oral diseases can be prevented by taking effective measures throughout life. Taking adequate measures in home care and avoiding unhealthy lifestyle can lead to disease prevention. Prevention of oral disease is important and can be achieved. ${ }^{4}$ Science-based, simple, and cheaper preventive methods exist, but they need to be judiciously promoted and implemented. Counseling pediatric dental patients by using persuasion and confrontation mostly fails in promoting behavior changes. ${ }^{5}$

Customary physician recommendation on health behavior is usually not met and can lead to regret in the mind of clinician and problem for patient. In 1983, research began on the use of motivational interviewing (MI). ${ }^{6}$ Motivational interviewing is an evidence-based approach used to impart health behavior change through counseling. Motivational interviewing utilizes a patientcentric and direct approach that sees discrepancies between a person's current attitude and their future perspective. ${ }^{7}$ A patientcentered talk facilitates discussion of psychological issues that might directly or indirectly have an effect on total health outcomes. Particularly, patient-centered communication, where patients' interest is paramount, has seen to be with increased parental satisfaction, adherence to pediatric treatment recommendations, and disclosure of psychological diseases. ${ }^{8}$ Motivational interviewing is based on the communication and attitude between the patient and the instructor, which is an integral part of pediatric dentist.
Department of Pediatric and Preventive Dentistry, Institute of Dental Sciences, Siksha 'O' Anusandhan (Deemed to be University), Bhubaneswar, Odisha, India

Corresponding Author: Sonu Acharya, Department of Pediatric and Preventive Dentistry, Institute of Dental Sciences, Siksha ' $O$ ' Anusandhan (Deemed to be University), Bhubaneswar, Odisha, India, Phone: +91 9937793095, e-mail: sonu_ain@yahoo.com

How to cite this article: Acharya S. Motivational Interviewing in Pediatric Dentistry: Role in Behavior Management. J South Asian Assoc Pediatr Dent 2019;2(2):69-72.

Source of support: Nil

Conflict of interest: None

Parents and caregivers are considered to be an integral component in the promotion of oral health of preschool children and so their oral health knowledge, attitudes, and behavior may influence early childhood oral health. Age-old dental health education programs with main focus on improving the parents oral health has not seen to be effective in increasing little children's oral health. Motivational interviewing is different from traditional health education approaches in that sense, that from the initial moment a person is prepared to start trying on the information imparted to them by an expert. Instead of the health professional performing the role of "expert," motivational interviewing tries to place the patient/parent in this significant role, making them to decide how they want to use this information in their own lives. This approach (MI) is better than counseling in pediatric dental setup as the onus is on parents/child to act on their oral health. So this approach should be used more often by the pediatric dentist as a preventive approach in oral diseases.

\section{What is Motivational Interviewing?}

Motivational interviewing is a way of talking with people about change related to things we often have mixed feelings about; it 
can be anything from exercise, diet, and any other issue we face in our lives. ${ }^{9}$ Motivational interviewing is defined as "a collaborative conversation style for strengthening a person's own motivation and commitment to change." ${ }^{\prime 9}$ This approach embodies "a mind-set and a heart-set" that includes partnership, acceptance, compassion and evocation. Motivational interviewing is a guidance that tells people to examine their own values and behaviors and to learn if change is required in these. It does not try to persuade people to change but instead makes them think whether a change is required in their particular behavior. Based on multiple health theories, MI focuses on persons motivation, internal will to change, and reduction in reactance. $^{10}$

\section{Elements of Motivational Interviewing}

The core beliefs are: ${ }^{11}$

\section{Spirit}

It is influenced by patients' own motivation to change rather than the change being imposed upon them. So, the clinicians' work is to support the patient in renaming and reframing the conflicting ideas, emotions, and attitudes whereas the patients' job is to resolve his/her ambivalence. Spirit of $\mathrm{MI}$ integrates the principles of autonomy, collaboration, and evocation. Autonomy means the patient is left on his own, whether he wants the change to occur, clinician would not force. Collaboration is a positive relation between the clinician and the patient to allow change. The clinicians try to evoke good thoughts for patient to accept the change rather than educate and confront the patient. Here the role of clinician is more of listening than talking. When practicing $\mathrm{Ml}$, it is important to make the patients know their own reasons for change. This model of intentional behavior change provides a frame for knowing the stages of behavior change. In this model, it is suggested that changers progress through 5 stages: precontemplation (not yet considering change), contemplation (considering change), preparation (planning and committing to change), action (making the behavior change), and maintenance (maintaining and sustaining long-term change). ${ }^{12}$ Motivational interviewing requires the healthcare professionals to understand the patient's stage on which to change to target their intervention effectively and efficiently.

\section{Principles}

The backbone of $\mathrm{MI}$ requires that healthcare professionals follow 4 principles: genuine expression of empathy, development of discrepancy between the patient's current behavior and his or her treatment goal, rolling with the client's resistance, and support of the patient's self-efficacy. ${ }^{13}$

- The clinician should show concern and understand what the patient conveys to him, i.e., being empathetic. This allows the patient to feel more comfortable and cared for and also allows them to open up more on the issues affecting them. In this, the clinician only patiently listens to the patient and should not interfere much in the talks. ${ }^{14}$

- Another principal is to develop a discrepancy on where the patient is now and where he/she would like to be. Allow the patient to make own argument for change. This will help patient to identify own goals. The clinician then focuses on the goals that are healthy and feasible.

- The third principle is rolling with resistance. The clinician should not confront and argue with the patient. In doing so, clinician avoids tension between patient and himself.
- The fourth principle is to support self-efficacy. It shows optimistic views on change that can be made. If the patient believes the change is possible, then he will be more than willing to follow instructions. The clinician should believe in patients' capacity to reach the goals.

\section{Elicit Change Talk}

Change talk is the patients' expression of desire, reason, ability, or need to make a change in their oral health behavior. Responses to change talk provide the opportunity to explore options and affirm a commitment to change.

\section{Person-centered Communication}

Motivational interviewing strategies help achieve desired behavior change. This consists of OARS, i.e., asking open-ended questions, affirmations, reflective listening, and summaries.

- Open-ended question - in contrast to closed questions, which generally require a simple yes/no or numeric answer, open questions do not direct a patient to respond in a particular manner. Instead, they enable a patient to think through and provide richer, fuller responses. The conversation should be started with words like how or what or describe so that the patient does most of the talking.

- Affirmations-sincere affirmations can help build a stronger relationship with a patient. These are the statements and gestures that help the patient to recognize strength and acknowledge behaviors that lead to positive change, no matter big or small.

- Reflective listening - this demonstrates that the clinician has accurately heard and understood a patient's communication. It also encourages further exploration of problems and feelings, thus strengthening the bond between the patient and clinician.

- Summaries-reinforces what has been said. Summary statements include trying to get the full picture of a patient's behavior, followed by checking with patient, making sure that they feel the healthcare professional has reflected their situation accurately. Summarizing helps in integrating the communication that has occurred between the patient and provider.

\section{Relation to Pediatric Dentistry}

Motivational interviewing is goal-oriented style of addressing which is designed to increase personal motivation and commitment to health behavior change by knowing and exploring patient's own reasons for needing a change. ${ }^{15}$ Motivational interviewing is found to be effective than no treatment and in most cases more efficient than even some active treatments. Pediatricians as well as pediatric dentists may be concerned that MI will take much of their time. However, once a professional learns the technique of $\mathrm{MI}$, they will realize that this does not take longer period of time. Actually, it can be used in brief sessions effectively. The persons' realization of good oral health behaviors will lead to decrease the risk of oral diseases. ${ }^{16}$ Health education might prompt in behavior change and the provision of oral health education lies with the dental professionals. ${ }^{17}$ In age-old health education scenarios, most of the healthcare professionals are trying in vain to increase the patients' knowledge without intrinsic motivations of patient. It has been seen that only educating and recommending things to people are not enough for changing behaviors. That is why something more than knowledge and education is necessary 
to improve oral health. ${ }^{18}$ Motivational interviewing is a type of consultation which helps the patient change their behavior with maximum internal motivation while facing minimum resistance. This method first came into existence for addicts (alcohol or tobacco) and since then, has been used for changes in lifestyle including diet, exercise, and weight loss. ${ }^{19}$ Several studies have shown that this technique works effectively in changing health behaviors in different populations, and it can also be used to change oral health behaviors. ${ }^{20}$ Traditional approaches with the main focus to improve parental oral health knowledge have not been effective in improving preschool children's oral health. ${ }^{21}$ Behavior change techniques (BCT), including face-to-face counseling, have been effective in almost all primary preventions. ${ }^{22}$ Behavior change techniques have been described as an observable, replicable, and irreducible component of an intervention designed to alter or redirect causal processed that regulate behavior. ${ }^{23}$ Though not strictly a theory of behavior change, MI does share some elements of the transtheoretical model (TTM) as proposed by Prochaska et al. ${ }^{24}$ Working with people of addictive behavior, the TTM was made so as to understand self-made and professionally assisted changes in health behavior. In spite of a big body of evidence from research works, the potential of $\mathrm{Ml}$ in dental healthcare is not well understood. A recent systematic review on the effectiveness of MI compared to conventional health education (CE) suggests that MI outperformed CE in improving oral health behaviors in infants and preschool children, mainly in relation to oral hygiene, but not in dietary habits. ${ }^{25}$ The usefulness of $\mathrm{Ml}$ in improving oral health may therefore still be considered controversial. Nevertheless, a recent evidence-based national clinical guideline for caries prevention from the UK states oral health promotion interventions should be based on recognized health theory behavior and models such as MI. ${ }^{26}$ Motivational interviewing can be used in pediatric dentistry for improved adherence to proper brushing techniques, flossing, and application of fluoride varnish.

The most common idea of caries among the general population is that of a cavity/hole in the teeth; moreover, parents tend to seek dental treatment/advice only after it starts paining or a swelling comes. ${ }^{27}$ Although restoration limits the destruction caused, it is unable to stop the pathological process of development of caries. Since the 1960s, dental practice has been mainly focused on preventing diseases. ${ }^{28}$ Educational methods for the promotion of health have been evaluated which have not been found to be effective in modifying habits or reducing caries and they cannot modify behaviors too. ${ }^{29}$ Here the MI can be more effective for prevention of caries in children. ${ }^{30}$ Weinstein et al. used this type of tool for the first time in application to preventive behaviors among the mothers of infants at a high risk of developing caries from an early age. ${ }^{31}$ Motivational interviewing is found to be effective than the available educational programs in preventing caries and decreasing bacterial plaque. ${ }^{32}$ It was also found that an intervention based on the principles of motivational interviewing style was more effective in reducing the number of surfaces affected by early childhood. ${ }^{33}$ Traditional dental health education approaches with a main focus on improving parental oral health knowledge have not been effective in improving preschool children's oral health. ${ }^{34}$ Motivational interviewing has shown to be more effective in pediatric oral care through prevention. Here the parents are motivated to take care, letting them decide how to interpret and integrate information in the context of their lives own and social circumstances and whether it is relevant to their children. ${ }^{35,36}$ Despite $\mathrm{MI}$ being said to be better than traditional educational programs, there would be barriers to change like child's nonacceptance of new brushing regimes, toothpaste use, and change from feeding bottle to cup. The use of $\mathrm{MI}$ as an additional tool to periodontal therapy may have a positive influence on clinical periodontal parameters and psychological factors related to oral hygiene (self-efficacy). ${ }^{37}$ Although not directly linked to behavior change, improving the knowledge and awareness of parents and caregivers is a key element of dental prevention in preschool children. Miller and Rollnick state that for a person to change, they must feel both confident in their ability to change and believe the change is important to them. ${ }^{38}$

\section{Conclusion}

The MI technique has created an opening about the importance the patient attaches with a desired behavior and their confidence in changing that behavior. From this place, we can communicate about wishes, set specific goals, and simultaneously identify strategies to overcome barriers and build confidence. The parents as well as the child should show behavior change through MI to make the attempt of improving oral health worthwhile. Motivational interviewing is an effective tool in behavior change technique in controlling childhood dental diseases like ECC. Much work has to be done to improve the role of $\mathrm{MI}$ in disease prevention in children.

\section{References}

1. Petersen PE. Challenges to improvement of oral health in the 21st century - the approach of the WHO Global Oral Health Programme. Int Dent J 2004;54(6 Suppl 1):329-343. DOI: 10.1111/j.1875-595X.2004. tb00009.x.

2. Petersen $P E$, Bourgeois $D$, Ogawa $H$, et al. The global burden of oral diseases and risks to oral health. Bull World Health Org 2005;83(9):661-669.

3. World Health Organization. WHO Bulletin special theme on oral health. Geneva: WHO; 2005.

4. Brown LF. Research in dental health education and health promotion: a review of the literature. Health Educ Q 1994;21(1):83-102. DOI: 10.1177/109019819402100109.

5. Nash DA. Pediatric oral health therapists are important to address the access to care problem for children. Pediatr Dent 2009;31(7):464-466.

6. Miller WR, Rollnick S, Butler BC. Motivational interviewing in healthcare. New York: Guilford; 2008; p. 210.

7. Weinstein P. Motivational interviewing concepts and the relationship to risk management and patient counselling. J Calif Dent Assoc 2011;39(10):742-745.

8. Yevlahova D, Satur J. Models for individual oral health promotion and their effectiveness: a systematic review. Aust Dent J 2009;54(3):190197. DOI: 10.1111/j.1834-7819.2009.01118.x.

9. Noordman J, van der Weijden T, van Dulman S. Communicationrelated behaviour change techniques used in face-to-face lifestyle interventions in primary care: a systematic review of the literature. Patient Educ Couns 2012;89(2):227-244. DOI: 10.1016/j. pec.2012.07.006

10. Resnicow K, Davis R, Rollinick D. Motivational interviewing for pediatric obesity: conceptual issues and evidence reviews.J Am Diet Assoc 2006;106(12):2024-2033. DOI: 10.1016/j.jada.2006.09.015.

11. Hettema J, Steele J, Miller WR. Motivational interviewing. Annu Rev Clin Psychol 2005;1:91-111. DOI: 10.1146/annurev. clinpsy.1.102803.143833.

12. Lundahl B, Burke BL. The effectiveness and applicability of motivational interviewing: a practice-friendly review of four meta-analyses. J Clin Psychol 2009;65(11):1232-1245. DOI: 10.1002/ jclp.20638. 
13. Lundahl B, Moleni T, Burke BL, et al. Motivational interviewing in medical care settings: a systematic review and meta-analysis of randomized controlled trials. Patient Educ Couns 2013;93(2):156-168. DOI: 10.1016/j.pec.2013.07.012

14. Erickson SJ, Gerstle M, Feldstein SW. Brief interventions and motivational inter viewing with children, adolescents, and their parents in pediatric settings. Arch Pediatr Adolesc Med 2005;159(12):1173-1180. DOI: 10.1001/archpedi.159.12.1173.

15. Tinanoff N, Daley NS, O-Sullivan DM, et al. Failure of intense preventive efforts to arrest early childhood and rampant caries: three case reports. Pediatr Dent 1999;21(3):160-163.

16. Schwartz RP, Hamre R, Dietz WH, et al. Office-based motivational interviewing to prevent childhood obesity. Arch Pediatr Adolesc Med 2007;161(5):495-501. DOI: 10.1001/archpedi.161.5.495.

17. Ramos-Gomez F, Crystal YO, Domejean S, et al. Minimal intervention dentistry: part 3. Paediatric dental care - prevention and intervention protocols using caries risk assessment for infants and young children. Br Dent J 2012;213(10):501-508. DOI: 10.1038/sj.bdj.2012.1040.

18. Suarez M, Mullins S. Motivational interviewing and pediatric health behavior interventions. J Dev Behav Pediatr 2008;29(5):417-428. DOI: 10.1097/DBP.0b013e31818888b4.

19. Moyers TB, Martin T, Manuel JK, et al. Revised Global Scales: Motivational Interviewing Treatment Integrity 3.0 (MITI 3.0) 2007.

20. Gao X, Lo ECM, ChingChingKot S, et al. Motivational interviewing in improving oral health: a systematic review of randomized controlled trials. J Periodontol 2013;85(3):426-437. DOI: 10.1902/jop.2013.130205.

21. Weinstein $P$, Harrison R, Benton T. Motivating parents to prevent caries in their young children. J Am Dent Assoc 2004;135(6):731-738. DOI: 10.14219/jada.archive.2004.0299.

22. Weinstein P, Harrison R, Benton T. Motivating mothers to prevent caries: confirming the beneficial effect of counselling. J Am Dent Assoc 2006;137(6):789-793. DOI: 10.14219/jada.archive.2006.0291.

23. Harrison R, Benton T, Everson Stewart $\mathrm{S}$, et al. Effect of motivational interviewing on rates of early childhood caries: a randomized controlled trial. Pediatr Dent 2007;29(1):16-22.

24. Prochaska JO, DiClimente CC. The transtheoretical approach: crossing traditional boundaries of therapy. Illinois: Don Jones/Irwin; 1984.

25. Ismail Al, Odersma S, Willem Jedele JM, et al. Evaluation of a brief tailored motivational intervention to prevent early childhood caries. Community Dent Oral Epidemiol 2011;39(5):433-448. DOI: 10.1111/j.1600-0528.2011.00613.x.

26. Scottish Intercollegiate Guideline Network (SIGN). Dental interventions to prevent caries in children. Edinburgh: Healthcare Improvement Scotland; 2014.
27. Naidu R, Nunn J, Irwin JD. The effect of motivational interviewing on oral healthcare knowledge, attitudes and behaviour of parents and caregivers of preschool children: an exploratory cluster randomised controlled study. BMC Oral Health 2015;15:101. DOI: 10.1186/s12903015-0068-9.

28. Michie $S$, Richardson $M$, Johnston $M$, et al. The behaviour change technique (v1) of 93 hierarchically clustered techniques: building an international consensus for the reporting of behavior change interventions. Ann Behav Med 2013:46:46-81. DOI: 10.1007/s12160013-9486-6.

29. Naidu R, Nunn J, Kelly A. Socio-behavioural factors and early childhood caries: a cross-sectional study of preschool children in central Trinidad. BMC Oral Health 2013;13:30. DOI: 10.1186/1472-683113-30.

30. Finlayson T, Siefert K, Ismail Al, et al. Reliability and validity of brief measures of oral health-related knowledge, fatalism and self-efficacy in mothers of African American children. Pediatr Dent 2005;27(5):422448.

31. Weinstein PW. Motivate Your Dental Patients A Workbook: The Public Health/Paediatric Edition. Seattle: University of Washington; 2002.

32. Britt $\mathrm{E}$, Hudson SM, Blampied NM. Motivational interviewing in health settings: a review. Patient Educ Couns 2004;53(2):147-155. DOI: 10.1016/S0738-3991(03)00141-1.

33. Colvara BC, Faustino-Silva DD, Meyer E, et al. Motivational interviewing in preventing early childhood caries in primary healthcare: a community-based randomized cluster trial. J Dent Educ 2019;83:585-594. DOI: 10.1016/j.jpeds.2018.05.016.

34. Freudenthal JJ, Bowen DM. Motivational interviewing to decrease parental risk-related behaviors for early childhood caries. J Dent Hyg 2010;84(1):29-34.

35. Watt R. Motivational interviewing may be effective in dental settings. Evid Based Dent 2010;11(1):13. DOI: 10.1038/sj.ebd.6400702.

36. Hooley M, Skouteris $\mathrm{H}$, Boganin $\mathrm{C}$, et al. Parental influence and the development of dental caries in children aged 0-6 years: a systematic review of the literature. J Dent 2012;40(11):873-885. DOI: 10.1016/j. jdent.2012.07.013.

37. Jönsson B, Ohrn K, Lindberg P, et al. Evaluation of an individually tailored oral health educational programme on periodontal health. J Clin Periodontol 2010;37(10):912-919. DOI: 10.1111/j.1600051X.2010.01590.x

38. Miller WR. A small study of training in motivational interviewing: does one workshop change clinician and client behavior? Behav Cogn Psychother 2001;29(4):457-471. DOI: 10.1017/S135246580100 4064. 